\title{
Adolescent Feeding: Nutritional Risk Factors
}

\author{
Joaquín Carrasco-Luna ${ }^{1,2}$ Marie Gombert ${ }^{1}$ Álvaro Carrasco-García ${ }^{2}$ Pilar Codoñer-Franch ${ }^{1,3}$
}

${ }^{1}$ Department of Pediatrics, Obstetrics, and Gynecology, University of Valencia, Valencia, Spain

2 Department of Experimental Science, School Catholic University of Valencia, Valencia, Spain

${ }^{3}$ Department of Pediatrics, Dr. Peset University Hospital, Valencia, Address for correspondence Joaquin Carrasco-Luna, PhD,
Department of Pediatrics, Obstetrics, and Gynecology, Faculty of Medicine, University of Valencia, Avda Blasco Ibañez 15, 46010 Valencia, Spain (e-mail: Joaquin.carrasco@uv.es). Spain

J Child Sci 2018;8:e99-e105.

\begin{abstract}
Keywords

- adolescent nutritional requirements

- energy requirements

- nutritional risk

- meal pattern irregularities

- eating disorders

The aim of this review is to describe adolescent nutritional requirements from a scientific, nutritional, and psychosocial point of view, emphasizing the main risks of malnutrition at this age. Currently, too many teenagers are alone at home and prepare their own meals. The influence of friends replaces parental rules. The habits of adolescents are characterized by a tendency to skip meals, especially breakfast, and, less frequently, the midday meal; to purchase carry-out meals away from home; to consume snacks, especially sweets; to eat at fast food restaurants, almost always with high-calorie content; and to eat fried foods, soft drinks, and sweets. Toxic habits, such as smoking, alcohol, and drugs, interfere with a healthy diet, as well. Physical activity usually decreases during adolescence, particularly in girls. The lack of physical activity is due to a precarious knowledge of the benefits associated with practicing physical activity, low motivation, time constraints, and, in many cases, the lack of adequate facilities. Adolescents interested in a body image in accordance with modern ideals follow restrictive and unbalanced diets without any nutritional basis, which they themselves planned. These behaviors increase the risk of nutritional alterations, such as noncompliance with nutritional requirements, meal pattern irregularities, nutritional problems due to low nutrient intake, and self-esteem issues and frustration. In general, in this age group, there is an increase in protein consumption and salt content, often with a supply of unbalanced nutrients, high-fat diets (35$50 \%$ of total calories), and low polyunsaturated/saturated fat ratio. In addition, adolescents consume a low level of complex carbohydrates, fiber, fruits, and vegetables.
\end{abstract}

\section{Introduction}

\section{Definition of Adolescence}

Adolescence is a period of life with specific health and developmental needs and is a transitional phase that leads to adulthood. UNICEF defines adolescence "as a time of great physical and emotional changes that essentially transform the child into an adult." Adolescence starts with pubertal

received

June 29, 2018

accepted after revision

July 1,2018
Issue Theme Nutrition in Child Health Conditions; Guest Editor: Pilar Codoñer Franch, MD, PhD.

DOI https://doi.org/ 10.1055/s-0038-1669436. ISSN 2474-5871. changes and ends with the full development of the organism. In this period, personality, independence, and self-affirmation are defined.

At this developmental stage, growth is very important and is closely related to the nutritional requirements of adolescents so that the maximum peak of nutritional needs perfectly matches the maximum growth rate.

Copyright $\odot 2018$ Georg Thieme Verlag License terms KG Stuttgart · New York

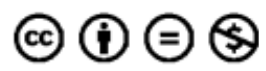


The World Health Organization (WHO) describes adolescence as the period between 12 and 18 years, although adolescence can be more broadly defined as between 11 and 19 years. ${ }^{1,2}$ Two phases can be considered in this period of life:

1. Early adolescence, with the onset of puberty between 10 and 14 years in girls and between 12 and 16 years in boys. This period encompasses a series of biological changes, including sexual maturation, growth spurt, and modification in body composition with a marked increase in lean mass in men, mainly by the proportion of muscle mass, and with increasing fat mass in women. These physiological changes make energy and nutrient requirements not only very high but also different for both sexes. ${ }^{3-5}$

2. Late adolescence, between 15 and 19 years, which ends the biological growth and psychological maturation. In this period, the bone mass peak is reached, increasing weight by $50 \%$, height by $25 \%$, and skeletal mass by $50 \%$ of adult status.

\section{Nutritional Requirements}

In adolescents, energy and nutrients are needed not only for the maintenance of bodily functions but also for very high growth and development in a short period of time, creating increased demands for energy and nutrients.

It is essential that young people learn that proper nutrition and regular physical exercise, practiced together, are the main basis of a healthy lifestyle and are the most important protective factors in the fight against future diseases. The search for personal identity can be an opportunity to consolidate food habits that are maintained during adult life. Good nutrition and a healthy diet (adequate, sufficient, balanced and varied) will result, in most cases, in a healthy adult individual.

Nutritional requirements are usually indicated according to chronological age, but in adolescence, due to variance among individuals during this period, many cases do not coincide with biological age; thus, it is preferable to propose nutritional requirements according to height, weight, or the period of sexual maturation.

\section{Energy Requirements}

Total daily energy expenditure (TDEE) is composed of the energy costs of the processes essential for life (basal metabolic rate [BMR], $60-80 \%$ of TDEE); the energy expended to digest, absorb, and convert food (diet-induced thermogenesis, 10\%); and the energy expended during physical activities ${ }^{6}$ (activity energy expenditure, $\sim 15-30 \%)$. BMR corresponds to the expenditure of energy at rest and represents the number of calories required for a 24-hour period by the body during a nonactive period. There are different equations for the calculation of BMR expenditure ${ }^{7}$ ( - Table $\mathbf{1}$ ).

The thermic effect of food is the increase in energy expenditure associated with food. The effect is also known as the specific dynamic action of food and as diet-induced thermogenesis. This process represents the augmentation in metabolism attributable to the digestion, absorption, processing, and storage of food and its components. There is an
Table 1 Different equations for basal metabolic rate (BMR) calculation $^{7-11}$

\begin{tabular}{|l|l|}
\hline Harris-Benedict Eq. (1918-1919) \\
\hline Men & $\begin{array}{l}\text { BMR }=66.5+(13.75 \times \text { weight })+ \\
(5.003 \times \text { height })-(6.775 \times \text { age })\end{array}$ \\
\hline Women & $\begin{array}{l}\text { BMR }=655.1+(9.563 \times \text { weight })+ \\
(1.850 \times \text { height })-(4.676 \times \text { age })\end{array}$ \\
\hline $\begin{array}{l}\text { Harris-Benedict equations revised by Mifflin and St Jeor in } \\
1990\end{array}$ & $\begin{array}{l}\text { BMR }=(10 \times \text { weight })+ \\
(6.25 \times \text { height })-(5 \times \text { age })+5\end{array}$ \\
\hline Men & $\begin{array}{l}\text { BMR }=(10 \times \text { weight })+ \\
(6.25 \times \text { height })-(5 \times \text { age })-161\end{array}$ \\
\hline Women & $\begin{array}{l}\text { BMR }=(16.252 \times \text { weight })+ \\
(1.372 \times \text { height })+515.2\end{array}$ \\
\hline Schöfield equation for adolescents $(10-18$ years $)$ \\
\hline Men & $\begin{array}{l}\text { BMR }=(8.365 \times \text { weight })+ \\
(4.656 \times \text { height })+200\end{array}$ \\
\hline Women & \begin{tabular}{l}
$(17.5 \times$ weight $)+651$ \\
\hline WHO 1985 (10-18 years $)$
\end{tabular} \\
\hline Men & $(12.2 \times$ weight $)+746$ \\
\hline Women
\end{tabular}

Note: For the calculation of BMR, the weight is taken in $\mathrm{kg}$, the height in $\mathrm{cm}$ and the age in years.

increase in BMR of approximately 5 to $15 \%$ depending on the size and composition of the meal.

Physical activity is another factor involved in daily energy expenditure. The energy spent depends on duration and intensity. In this way, to calculate the TDEE, multiply the BMR by the corresponding activity factor. ${ }^{12}$

- Sedentary: Little or no exercise (desk job), $\mathrm{TDEE}=1.2 \times \mathrm{BMR}$.

- Lightly active: Light exercise/sports (1-3 days/week), TDEE $=1.375 \times$ BMR.

- Moderately active: Moderate exercise/sports (3-5 days/ week), TDEE $=1.55 \times$ BMR.

- Very active: Heavy exercise/sports (6-7 days/week), TDEE $=1.725 \times$ BMR.

- Extremely active: Very heavy exercise/physical job/training $(2 \times$ day $)$, TDEE $=1.9 \times$ BMR.

By sex, the average energy requirement is estimated to be between $2,750 \mathrm{kcal}$ in boys and 2,200 kcal in girls. ${ }^{13}$

\section{Nutrient Requirements}

Due to the rate of development and the marked sexual dimorphism during adolescence, the energy, macronutrient, and micronutrient requirements surpass those of any other period of life. Adolescents are very sensitive to caloric restrictions and protein deficiencies, as well as some vitamins and trace elements. To estimate requirements, it is necessary to consider not only the chronological age but also the sex, maturation state of puberty, individual size, and growth rate $^{7,13}$ (- Table 2). 
Table 2 Anthropometry and energy requirements ${ }^{3-5,7,13}$

\begin{tabular}{|l|l|l|}
\hline & Boys & Girls \\
\hline Lean mass $(\mathrm{kg})$ & $27-62$ & $25-43$ \\
\hline Fat mass $(\mathrm{kg})$ & $7-9$ & $5-14$ \\
\hline Height $(\mathrm{cm})$ & $150-176$ & $150-164$ \\
\hline Weight $(\mathrm{kg})$ & $45-72$ & $46-58$ \\
\hline Energy $(\mathrm{kcal} /$ day) & $2,500-3,000$ & $1,800-2,400$ \\
\hline
\end{tabular}

\section{Macronutrients}

\section{Proteins}

Protein requirements are established according to the need to maintain the body mass and to obtain adequate growth. The data from adolescents are based on extrapolations from nitrogen balance studies conducted at other ages. The maximum limit has been established as twice the recommendations. ${ }^{7}$

It should be noted that at this age, males gain weight more quickly, increasing muscle and skeletal mass, while females tend to accumulate fat. Thus, the protein requirements are slightly higher in boys than those in girls (-Table 3 ).

A healthy diet should contain 10 to $30 \%$ of calories based on protein intake, which should never be less than $10 \%$, of which two-thirds should be of animal origin and one-third of high biological value. These intakes provide the amount of essential amino acids required by the accelerated growth.

Table 3 Nutritional recommendations per day in adolescents between 14 and 18 years ${ }^{7,14-17}$

\begin{tabular}{|c|c|c|}
\hline & Boys & Girls \\
\hline \multicolumn{3}{|l|}{ Macronutrients } \\
\hline Fats (\%) & $25-35$ & $25-35$ \\
\hline Fats (g) & $60-86$ & $50-70$ \\
\hline Omega-6\&9 (\%) & $5-10$ & $5-10$ \\
\hline Omega-3 (\%) & $0.6-1.2$ & $0.6-1.2$ \\
\hline Carbohydrates (\%) & $45-65$ & $45-65$ \\
\hline Proteins (\%) & $10-30$ & $10-30$ \\
\hline Proteins $(\mathrm{g} / \mathrm{kg})$ & $09-1.0$ & $0.8-1.0$ \\
\hline Proteins (g) & $45-59$ & $44-46$ \\
\hline Fiber $(g)$ & $25-38$ & $25-38$ \\
\hline \multicolumn{3}{|l|}{ Micronutrients } \\
\hline Riboflavin (mg) & $0.9-1.3$ & $0.9-1.0$ \\
\hline Biotin (mg) & $20-25$ & $20-25$ \\
\hline Calcium (mg) & $1,000-1,300$ & $900-1,300$ \\
\hline Iron (mg) & 15 & 18 \\
\hline Thiamine (mg) & $1.1-1.2$ & 0.9 \\
\hline Niacine (mg) & $12-20$ & $12-15$ \\
\hline Folic acid $(\mu \mathrm{g})$ & $200-300$ & $200-400$ \\
\hline Phosphorus (mg) & $1,055-1,250$ & $1,055-1,250$ \\
\hline Vitamin D $(\mu \mathrm{g})$ & $10-20$ & $10-20$ \\
\hline
\end{tabular}

\section{Carbohydrates}

Cereals and grains are the basis of plant-based diets. Higher consumption of whole grains is also associated with lower cardiovascular risk. Based on these considerations, carbohydrates must contribute more than $50 \%$ of the total energy consumed and be mainly provided by complex carbohydrates, which also constitute an important source of fiber. Refined sugars, however, should be limited to less than 8 to $10 \%$ of total energy because of their relationship to excessive weight gain. It should be noted that currently there is an increase in the consumption of liquid sugar by constantly adding new products to the diet, such as fruit juice, energy drinks, sports drinks, and other new options. ${ }^{14}$ The amount of sucrose in the daily diet should be limited, and the consumption of packaged juices and soft drinks should be limited to less than one serving per day in the juvenile population (-Table 3 ).

\section{Fat}

Although cardiovascular and coronary heart diseases typically present later in life, atherosclerotic lesions in the aorta and coronary arteries can begin to appear in childhood and are positively associated with elevated total and low-density lipoprotein cholesterol. Dietary saturated fatty acids and trans-fatty acids are strongly correlated with total and lowdensity lipoprotein cholesterol levels. Based on these factors, the dietary recommendations include a maximum of 25 to $35 \%$ of energy provided by fat, $7 \%$ by saturated fats (fatty meats, sausages, whole milk, butter, coconut oil, and palm oil), 10 to $15 \%$ by monounsaturated fat (olive oil), $13 \%$ by polyunsaturated fats (vegetable oils and fatty fish), $<1 \%$ from saturated trans fats (margarine, breakfast cereals, cookies, pastries, snacks, and ready-meals), and $300 \mathrm{mg}$ of cholesterol/day (egg yolks, fatty meats, and dairy products). ${ }^{15}$

If foods of animal origin are restricted, due to their high saturated fat content, a greater consumption of legumes should be recommended to ensure a sufficient supply of protein and specific nutrients (minerals, fat-soluble vitamins, riboflavin, pyridoxine, calcium, zinc, iron, iodine, and magnesium), whose lack could lead to growth deficits.

\section{Dietary Fibers}

Dietary fiber is a residue of plant-based food, which is resistant to hydrolysis by digestive enzymes and constitutes a heterogeneous mixture of polysaccharides and lignin. Fiber can reduce cholesterol absorption and produce short-chain fatty acids, causing longer lasting satiety and increasing stool bulkiness and fecal mass, thereby promoting a healthy intestinal habitat.

To ensure an adequate intake of dietary fiber, it is advisable to incorporate fruits, vegetables, and legumes into the diet at all meals and is the best way to prevent obesity and its comorbidities, as well as some types of cancer.

It is more beneficial to consume whole foods with high fiber content than isolated fiber. It is recommended to consume fruit instead of juice, and whole grains are better than processed cereals and refined flours. The recommended intakes range from 25 to $38 \mathrm{~g} /$ day. 


\section{Micronutrients}

\section{Vitamins}

In this age group, vitamins need to be increased with respect to other stages of childhood. It is required to increase the supply of thiamine, riboflavin, and niacin, which are involved in obtaining energy from macronutrients (carbohydrate metabolism). Vitamins $B_{6}$ and $B_{12}$, as well as folic acid, are necessary for protein and nucleic acid synthesis, and vitamins A, C, D, and E participate in the development of new cells and bone mineralization. ${ }^{16,17}$

The most effective way to avoid vitamin deficit is the consumption of a varied diet, including several servings of each of the four main food groups: meat and fish, milk and dairy products, cereals and legumes, and fruits and vegetables. Other recommendations are as follows: make three or more meals a day, control the amount of salt, and avoid alcohol, which can increase the requirements.

\section{Minerals}

Mineral needs are also high in adolescence, mainly iron, zinc, and calcium, which on some occasions cannot be covered by diet. There is a great demand for iron, due to an increase in lean mass, with an increase in the formation of myoglobin and blood volume and with iron deficiency being the most frequent nutritional deficit at this age. Iron deficiency is present in 10 to $15 \%$ of adolescents, is more frequent in athletes, and especially in women with abundant menstrual losses. For these cases, iron-rich foods and an adequate supply of vitamin C, which increases iron absorption, should be advised.

The latest Dietary Recommended Intake published for calcium, phosphorus, and magnesium establishes $1,300 \mathrm{mg} /$ day of calcium (the approximate content of $1 \mathrm{~L}$ of milk and/or dairy products) as an adequate intake in this age group. Hence, it is advisable to have $3 / 4$ to $1 \mathrm{~L}$ of milk per day, an amount that a high percentage of adolescents do not reach.
A varied and balanced diet, with the total recommended caloric intake, is the best guarantee for the correct intake of other minerals, such as zinc, magnesium, copper, chromium, phosphorus, and selenium. Zinc is essential for growth and sexual maturation. Diets that are low in proteins of animal origin do not completely cover daily needs. Thus, adolescents who ingest vegetarian diets are exposed to zinc deficiency. To avoid this deficiency, the consumption of peanuts, whole grains, and cheeses or sesame seeds (between 3 and $10 \mathrm{mg} / 100 \mathrm{~g}$ ) is recommended. ${ }^{18}$

In summary, the most appropriate way to meet the need for minerals is the consumption of a varied diet, in which 20 to $25 \%$ of calories come from animal foods, including at least 3/4 liter of milk or milk products.

\section{Recommendations for Adolescent Feeding}

In adolescence, body changes affect nutritional and dietary needs, and it is also the time to establish a healthy lifestyle and eating habits. ${ }^{15}$ The family environment is important to exert a favorable influence on the diet of adolescents because they consume 63 to $65 \%$ of their daily calories at home ${ }^{19}$ (-Table 4). Parents may encourage food consumption and restrict access to certain unhealthy foods, thus establishing a habit of greater consumption of vegetables and products rich in calcium and lower consumption fried foods and sugary soft drinks (-Table 5 ).

\section{Nutritional Risk in Adolescence}

In the period of adolescence, important quantities of macroand micronutrients are required. However, psychosocial factors, such as the independent personality common in adolescents, with popular sayings including, "I like what I like," and the rejection of family guidelines, add difficulty to achieving adequate nutrition. In addition, there is a pattern

Table 4 Schedule of feeding. Servings ${ }^{15,18,19}$

\begin{tabular}{|c|c|c|c|c|c|}
\hline Meals & $\begin{array}{l}\text { Calories } \\
(\%)\end{array}$ & Components & Daily servings & Weekly servings & Occasionally \\
\hline Breakfast & $20-25$ & $\begin{array}{l}\text { Whole cereals, fruit, } \\
\text { sometimes } \\
\text { ham or cold cuts }\end{array}$ & $\begin{array}{l}\text { - } 4-6 \text { servings of foods } \\
\text { rich in carbohydrates } \\
\text { - 2-4 milk rations } \\
\text { or derivatives } \\
\text { (as a source of calcium) }\end{array}$ & $\begin{array}{l}\text { - } \text { Rich protein content } \\
\text { of high biological } \\
\text { value } \\
\text { - } 2-4 \text { servings of } \\
\text { mixed legumes } \\
\text { - } 3-7 \text { servings of nuts }\end{array}$ & \multirow[t]{2}{*}{$\begin{array}{l}\text { Sausages and } \\
\text { fatty meats } \\
\text { butter, margarine, } \\
\text { and industrial } \\
\text { pastries }\end{array}$} \\
\hline Brunch & $5-10$ & A fruit, a yogurt & $\cdot$ & $\cdot$ & \\
\hline Lunch & $30-35$ & $\begin{array}{l}\text { 1st pasta, rice, legumes, } \\
\text { potatoes, or vegetables } \\
\text { and } 2 \text { nd fish, meat or } \\
\text { eggs and fruit } \\
\text { dessert salad }\end{array}$ & \multirow[t]{3}{*}{$\begin{array}{l}\text { - At least } 2-5 \text { servings of } \\
\text { various vegetables } \\
\text { - At least } 3 \text { servings of } \\
\text { fruit and juice } \\
\text { - } 2-3 \text { servings of olive oil } \\
\text { - } 4-8 \text { water rations }\end{array}$} & \multirow[t]{3}{*}{$\begin{array}{l}\text { - 3-4 servings of fish } \\
\cdot 3-4 \text { servings of } \\
\text { lean meat. } \\
\text { - 3-4 eggs }\end{array}$} & \multirow[t]{3}{*}{$\begin{array}{l}\text { Sweets, snacks, } \\
\text { soft drinks }\end{array}$} \\
\hline Snack & $5-10$ & Fruit and sandwich & & & \\
\hline Dinner & 25 & $\begin{array}{l}\text { Purees, soups, salads } \\
\text { and as a complement, } \\
\text { eggs, meat or fish } \\
\text { alternating food, } \\
\text { and fruit dessert }\end{array}$ & & & \\
\hline
\end{tabular}


Table 5 General recommendations ${ }^{1-3,7,21}$

\begin{tabular}{|c|c|}
\hline \multirow[t]{3}{*}{ Parents } & - Stimulate interest in health, cooking or nutrition \\
\hline & - Accept suggestions, whenever possible, regarding the meals that are prepared at home \\
\hline & - Do not buy foods not recommended and grill instead of frying \\
\hline \multirow[t]{5}{*}{ Adolescents } & - Foods must be sufficient, varied and balanced \\
\hline & - Keep four meals a day (breakfast, lunch, snack, and dinner) \\
\hline & - Do not stop take breakfast; it is recommended that it must be as varied as possible \\
\hline & - Perform at least 30 minutes of physical activity every day \\
\hline & $\begin{array}{l}\text { - Limit less than } 2 \text { hours each day to sedentary activities such as watching television, } \\
\text { video games, and computer use }\end{array}$ \\
\hline \multirow[t]{7}{*}{ Feeding } & $\begin{array}{l}\text { - Incorporate the intake of dietary fiber, increasing the intake of complex carbohydrates, } \\
\text { such as whole grains, vegetables, and fruits }\end{array}$ \\
\hline & - Decrease the amount of salt \\
\hline & - Decrease sugar intake. Avoid the consumption of sweets \\
\hline & - Drink water and avoid the consumption of packaged juices and soft drinks with high sugar content \\
\hline & - Increase the consumption of natural whole fruit, against industrial juice \\
\hline & - Decrease the use of saturated fats \\
\hline & - Eat more chicken and fish. Limit the intake of red meat \\
\hline
\end{tabular}

of social feeding at this age with the replacement of meals by "snacking" and fast-food snacks. This situation of less psychosocial stability leads to the questioning of "oneself." Social patterns and fashions influence body perception, which leads to a high nutritional risk and the development of different disorders. ${ }^{2,7,14}$

\section{Noncompliance with the Nutritional Requirements}

Imbalance situations are the most prominent threat among adolescents, since a positive or negative energy balance causes a situation of malnutrition (by defect or by excess) and therefore generates changes in the rate of growth and maturation.

The insufficient supply of nutrients can inhibit the secretion of gonadotropins, which affects pubertal development and growth with deficiency. On the other hand, imbalance due to excess causes situations of being overweight and obesity, dyslipidemia, hypertension, diabetes, alterations in bone mineralization, and eating disorders. ${ }^{20}$

\section{Special Situations}

\section{Elite Athletes}

In the calculation of energy expenditure, moderate physical activity is already included when assessing the total energy contribution $(2,750 \mathrm{kcal} /$ day for boys and 2,200 kcal/day for girls). If the adolescent also performs a competitive sport with periodic training, an individualized calculation, according to expenditure, will be required. In some sports or activities, in which the physical aspect is important, and a low weight increases performance, such as some modalities of gymnastics, races, or ballet, it is necessary to monitor the appearance of eating disorders, nutritional deficits, premature osteoporosis, and amenorrhea. ${ }^{7}$

\section{Pregnancy}

Pregnancy in adolescents is a situation of extreme nutritional risk. Approximately $10 \%$ of newborns of mothers 15 to 19 years have low birth weight. Therefore, in pregnancy, it is mandatory to supplement the diet of these young women with calories, protein, and essential nutrients, as well as vitamins and minerals to achieve full-term pregnancies under the best possible conditions. ${ }^{20}$

\section{Obesity}

Essentially, obesity is produced by the ingestion of hypercaloric diets and a marked decrease in physical activity, which is associated with behavioral disorders with special psychological traits and a very negative body image. Obesity generates a risk of emotional instability, introversion, and passivity. Thus, it is important to design nutritional interventions to prevent this situation.

Laziness, physical inactivity, and sedentary lifestyle, along with apathy, determine, in a large part of adolescents, a very important decrease in activity and physical exercise. At the same time, a worrying proliferation of the use of information and communication technologies (usually $>2$ hours per day devoted to TV, video games, the computer, and listening to music $)^{3,7}$ decreases energy expenditure.

\section{Meal Pattern Irregularities}

\section{Skipping Meals}

Skipping meals is the most frequent form of altered eating habits. It basically consists of the tendency to skip any meal or to scarcely eat. Skipping breakfast is usually more detrimental than skipping other meals, as breakfast should contribute to $25 \%$ of daily calories, and its absence or shortage diminishes attention span during the first classes of the day, 
resulting in poor intellectual and physical performance and affecting the intake of daily energy. ${ }^{1,21}$

\section{Snacking between Meals}

The adolescent's lifestyle often leads him/her to eat away from home, suppressing or restricting meals, which are often replaced by small intakes and snacks between main meals, including soft drinks, ice cream, or other foods of little nutritional high caloric value. ${ }^{16}$ These items are usually bought in stores, coffee shops, or vending machines. Such foods provide a high amount of energy with low nutrient density and an excessive intake of fats and simple sugars or salt, assuming between 10 and $30 \%$ of the total energy of the daily diet. The abuse of this type of food eliminates appetite and can displace foods and drinks of high nutritional interest. The consumption of these products should be only an occasional consumption option.

\section{Fast Food, Junk Food}

Frequent visits to fast food restaurants and the availability of precooked foods at home have also contributed to the change in eating habits. This dietary shift has promoted low consumption of fruits and vegetables and sources of protein with high biological value, such as meat, eggs and fiber, as well as deficits in micronutrients, vitamins, and minerals, ${ }^{1,7}$ such as iron, calcium, and vitamins $A$ and $C$. There is also an increase in the consumption of total fat, saturated fat, cholesterol, sugar, and sodium. The impact on the state of nutrition varies with the relative proportion of this type of food in the diet.

\section{Consumption of Alcohol}

The age of onset of alcohol consumption in Spain is 13 years. A total of $75.1 \%$ of adolescents aged 14 to 18 years have used alcohol in their lives. The intake of even moderate amounts of alcohol has an important impact on nutritional balance, mainly through two mechanisms: the reduction in food intake and changes in the bioavailability of certain nutrients. The intake of alcohol decreases the absorption of folic acid, thiamine, and vitamins $A, C$, and $B_{12}$, while increasing the urinary excretion of calcium, zinc, and magnesium.

Some adolescents, especially on weekends, drink variable amounts of alcohol, which provides empty calories without nutritional value. This habit has harmful effects on appetite and the digestive and nervous systems. In most cases, this consumption is associated with the introduction of smoking and the impaired metabolism of vitamin $\mathrm{C}$ and folate, increasing the lack of vitamin $\mathrm{E}^{1,2}$

\section{Self-Esteem}

Adolescents in developed countries are subjected to additional pressure, which arises from very rapid body changes, with insecurity and misunderstanding that somehow lead to visceral opposition to adults. On the other hand, some of the main worries are the Internet, advertising, the food industry, and self-image. Group opinion and the search for new models, such as heroes, artists, and companions, become a solution. All these factors have a specific weight and an excessive influence from the nutritional point of view. On many occasions, these influences lead adolescents to make drastic decisions regarding their diet. ${ }^{22}$

\section{Tracking Diets}

Advertising on diets and social communication networks are an instrument for disseminating healthy or dangerous habits according to the use they are given. ${ }^{20}$ The appearance of restrictive diets is due to an excessive concern about body image, based on a certain beauty (thinness) model, thus initiating slimming regimens that lead to an insufficient intake of many nutrients, especially in women, with an increase in physical activity or even an initiation of purging behaviors for weight maintenance. ${ }^{23}$ The adoption of vegan and vegetarian diets, with the absence of the ingestion of eggs and meat, favors the appearance of deficiencies, especially for vitamins D and B12, riboflavin, calcium, zinc, iron, and other trace elements. Therefore, we must be especially alert for the adoption of "fashionable" diets that are hypocaloric and nutritionally unbalanced, as well as the use or abuse of nutritional and non-nutritional supplements.

\section{Eating Disorders}

The voluntary restrictions of food intake can lead, in extreme situations, to eating disorders such as anorexia, bulimia, and others, which preferentially affect young adolescents. ${ }^{24}$ This effect is mainly due to the frequent rejection of body image and the excessive value of physical appearance, which leads to situations of rejecting oneself, dissatisfaction, and anxiety. ${ }^{25}$ Eating disorders have a relatively low prevalence of $\sim 1$ to $3 \%$ (with a ratio of $10: 1$ in girls), although 40 to $60 \%$ of adolescents acknowledge making some type of food restriction to control weight. ${ }^{7}$

\section{Main Problems}

In general, due to the main problems derived from changes in nutritional patterns and the variation in nutritional requirements with highly associated psychosocial factors, nutritional disorders are triggered in adolescents, so that they should follow general recommendations to avoid health problems. In general, we can determine that adolescents are at risk of increased protein and salt consumption, often with an unbalanced supply of nutrients, with high-fat diets (35-50\% of total calories) and low polyunsaturated/saturated fatty acid ratio. Most of the saturated fat comes from the consumption of meat, sausages, and pâtés, not from milk and other dairy-based foods or an excess of refined carbohydrates (-Table 5).

In contrast, adolescents consume low complex carbohydrates, fiber, and fruits and vegetables. According to a study of 2,516 individuals, $98 \%$ consume less than 5 servings a day of fruits and vegetables; $23 \%$ never eat legumes; $78.4 \%$ do not intake the recommended daily dairy rations; and in $68 \%$, the intake of fish is scarce and zero in $20 \%{ }^{1,2}$

\section{Conclusion}

Adolescence is a period of nutritional risk. Together with increased requirements due to growth spurts, this age group is in noncompliant with the nutritional requirements because 
of the psychological characteristics at this age. Pediatricians should be aware of these problems and incorporate adequate diagnostic and intervention strategies in the care of these special patients.

\section{Conflict of Interest}

None.

\section{References}

1 Varela Moreiras G. Libro blanco de la nutrición en España. Madrid: FEN; 2013:1-607. Available at: http://www.seedo.es/images/site/ documentacionConsenso/Libro_Blanco_Nutricion_Esp-2013.pdf. Accessed April, 2018

2 Rivero Urgell M, Moreno Aznar LA, Dalmau Serra J, Moreno Villares JM, Aliaga Pérez A, García Perea A, Varela Moreiras G, Ávila Torres JM. Libro blanco de la nutrición infantil. Zaragoza: Prensas de la Universidad de Zaragoza; 2015:1-530. Available at: http://www.aeped.es/sites/default/files/documentos/libro_blanco_de_la_nutricion_infantil.pdf. Accessed April, 2018

3 Marugán de Miguelsanz JM, Monasterio Corral L, Pavón Belinchón MP. Alimentación en el adolescente. In: SEGHNP-AEP. Protocolos diagnóstico-terapéuticos de Gastroenterología, Hepatología y Nutrición Pediátrica. Madrid: Ergon SA; 2010:307-312. Available at: https:// www.aeped.es/sites/default/files/documentos/alimentacion_adolescente.pdf. Accessed April, 2018

4 Lister NB, Gow ML, Chisholm K, Grunseit A, Garnett SP, Baur LA. Nutritional adequacy of diets for adolescents with overweight and obesity: considerations for dietetic practice. Eur J Clin Nutr 2017; 71(05):646-651

5 Weber DR, Leonard MB, Shults J, Zemel BS. A comparison of fat and lean body mass index to BMI for the identification of metabolic syndrome in children and adolescents. J Clin Endocrinol Metab 2014;99(09):3208-3216

6 Lam YY, Ravussin E. Analysis of energy metabolism in humans: a review of methodologies. Mol Metab 2016;5(11):1057-1071

7 Moreno Aznar LA, Rodríguez Martínez G. Nutrición en la adolescencia. In: Gil Hernández A, ed. Tratado de Nutrición 3rd ed. Madrid: Editorial Panamericana; 2017:259-273

8 Harris JA, Benedict FG. A biometric study of basal metabolism in man. Proc Natl Acad Sci U S A 1918;4(12):370-373

9 Schofield WN. Predicting basal metabolic rate, new standards and review of previous work. Hum Nutr Clin Nutr 1985;39(Suppl 1): $5-41$

10 Report of a joint FAO/WHO/UNU Expert Consultation. Energy and protein requirements. World Health Organ Tech Rep Ser 1985; 724:1-206

11 Müller MJ, Bosy-Westphal A, Klaus S, et al. World Health Organization equations have shortcomings for predicting resting energy expenditure in persons from a modern, affluent population: generation of a new reference standard from a retrospective analysis of a German database of resting energy expenditure. Am J Clin Nutr 2004;80(05):1379-1390

12 Wildman REC. Metabolism, energy balance and body weight and composition. In: Medeiros DM, Wildman REC, eds. Advance Human Nutrition. 4th ed. Boston: Jones \& Bartlett learning; 2018: 212-215

13 Dror DK, Allen LH. Dairy product intake in children and adolescents in developed countries: trends, nutritional contribution, and a review of association with health outcomes. Nutr Rev 2014; 72(02):68-81

14 Moro M, Málaga S, Madero L. Cruz Tratado de Pediatría, 11th ed. Madrid: Editorial Médica Panamericana; 2014

15 U.S. Department of Health and Human Services and U.S. Department of Agriculture. 2015 - 2020 Dietary Guidelines for Americans 8th ed; 2015. Available at https://health.gov/dietaryguidelines/2015/guidelines/. Accessed April, 2018

16 Iglesia I, Huybrechts I, González-Gross M, et al. Folate and vitamin B12 concentrations are associated with plasma DHA and EPA fatty acids in European adolescents: the Healthy Lifestyle in Europe by Nutrition in Adolescence (HELENA) study. Br J Nutr 2017;117(01): 124-133

17 Smith TJ, Tripkovic L, Lanham-New SA, Hart KH. Vitamin D in adolescence: evidence-based dietary requirements and implications for public health policy. Proc Nutr Soc 2017;4:1-10

18 Agnoli C, Baroni L, Bertini I, et al. Position paper on vegetarian diets from the working group of the Italian Society of Human Nutrition. Nutr Metab Cardiovasc Dis 2017;27(12):1037-1052

19 Poti JM, Popkin BM. Trends in energy intake among US children by eating location and food source, 1977-2006. J Am Diet Assoc 2011; 111(08):1156-1164

20 Christian P, Smith ER. Adolescent undernutrition: global burden, physiology, and nutritional risks. Ann Nutr Metab 2018;72(04): 316-328

21 Hallström L, Labayen I, Ruiz JR, et al; HELENA Study Group. Breakfast consumption and CVD risk factors in European adolescents: the HELENA (Healthy Lifestyle in Europe by Nutrition in Adolescence) Study. Public Health Nutr 2013;16(07):1296-1305

22 Jo S, Chen AC. Internet well-being in adolescents: a concept analysis. Stud Health Technol Inform 2018;250:33

23 Zarychta K, Chan CKY, Kruk M, Luszczynska A. Body satisfaction and body weight in under- and healthy-weight adolescents: mediating effects of restrictive dieting, healthy and unhealthy food intake. Eat Weight Disord 2018; [Epub ahead of print]

24 Herpertz-Dahlmann B. Adolescent eating disorders: update on definitions, symptomatology, epidemiology, and comorbidity. Child Adolesc Psychiatr Clin N Am 2015;24(01):177-196

25 Föcker M, Knoll S, Hebebrand J. Anorexia nervosa. Eur Child Adolesc Psychiatry 2013;22(Suppl 1):S29-S35 